\title{
Hepatic Sarcoidosis in a Patient with Chronic Hepatitis B Virus Infection
}

\author{
Hye-Sun Park ${ }^{1}$, Hyemin Kim ${ }^{2}$, Ji-Yeon Lee ${ }^{1}$, Su-Young Jung ${ }^{1}$, Seunghee Han ${ }^{1}$, Yong-Beom Park ${ }^{3}$, Soo-Kon Lee ${ }^{3}$, \\ Sang Hoon Ahn ${ }^{1,4}$, Sang-Won Lee ${ }^{3}$ \\ Departments of ${ }^{1}$ Internal Medicine, ${ }^{2}$ Pathology, ${ }^{3}$ Division of Rheumatology, Department of Internal Medicine, ${ }^{4}$ Institute of Gastroenterology, \\ Yonsei University College of Medicine, Seoul, Korea
}

\begin{abstract}
Sarcoidosis is a systemic inflammatory granulomatous disease affecting multiple organs, including liver, spleen, heart, eyes, and skin. Liver involvement is reported in $11.5 \%$ of cases and many studies have reported on the association between hepatitis $\mathrm{C}$ virus infection and sarcoidosis. However, the role of hepatitis B virus (HBV) infection as a trigger for sarcoidosis has never been reported. We describe a case of hepatic sarcoidosis in a patient with chronic hepatitis B infection, with a possible link between the two. It is the first case report of a patient with interferon- $\alpha$-naïve chronic HBV infection presenting with hepatic sarcoidosis accompanied by portal hypertension and liver cirrhosis. (J Rheum Dis 2015;22:200-204)
\end{abstract}

Key Words. Sarcoidosis, Hepatitis B virus, Liver cirrhosis, Portal hypertension

\section{INTRODUCTION}

Sarcoidosis is an autoimmune disease which is characterized by systemic non-caseating granuloma in multiple organs $[1,2]$. It has been reported to be able to occur in every race and age, and the incidence ranges 1 to 40 cases per 100,000 persons worldwide [2]. However, the incidence of sarcoidosis in Asian is less than that of Caucasian: 1 to 2 cases per 100,000 in Japan and 0.13 cases per 100,000 in Korea [3,4]. Although sarcoidosis can be suspected when patients present disease-related clinical and radiologic features, typical histologic findings are essential to make a diagnosis [5].

Sarcoidosis commonly involves lungs and lymph nodes up to $90 \%$ and it can also affect almost all organs including liver, spleen, heart, eyes and skin [2]. Liver involvement can be found in $11.5 \%$ of the cases [6], and it is usually asymptomatic. Only $5 \%$ to $30 \%$ patients experience atypical symptoms such as nausea, vomiting and abdominal pain [7]. The progressive complication like liver cir- rhosis is rarely presented at a rate less than $1 \%$ [2].

There have been several reports regarding the association between hepatitis C virus (HCV) and hepatic sarcoidosis. Interferon- $\alpha$ (INF- $\alpha$ ), which was used to treat $\mathrm{HCV}$, was first considered to induce hepatic sarcoidosis. And then there were accumulating reports that HCV itself can be an initiating factor for hepatic sarcoidosis [8]. However the association between the development of sarcoidosis and hepatitis B virus (HBV) was not clarified and there was no case report on sarcoidosis in patients with chronic HBV infection who were not treated by INF- $\alpha$. Hence, we first describe a patient with INF- $\alpha$-naïve chronic HBV infection presenting hepatic sarcoidosis accompanied by portal hypertension and liver cirrhosis.

\section{CASE REPORT}

A 49-year-old woman with chronic HBV infection was referred to our hospital for loss of appetite and mild

\footnotetext{
Received : June 9, 2014, Revised (1st) July 14, 2014, (2nd) August 11, 2014, Accepted : August 19, 2014

Corresponding to : Sang-Won Lee, Division of Rheumatology, Department of Internal Medicine, Yonsei University College of Medicine, 50-1 Yonsei-ro, Seodaemun-gu, Seoul 120-752, Korea. E-mail: sangwonlee@yuhs.ac 
ab.dominal bloating and discomfort. She was diagnosed with HBV infection 10 years ago, but she has been on regular check-ups without the treatment for chronic HBV infection so far. It was assumed that she had been infected with HBV by perinatal transmission as her mother and siblings had also been diagnosed with HBV infection. Other than B-viral hepatitis, she had no medical history.

Table 1. Laboratory data

\begin{tabular}{lcc}
\hline \hline \multicolumn{1}{c}{ Variable } & $\begin{array}{c}\text { Patient's } \\
\text { result }\end{array}$ & Reference range \\
\hline White cell count $(/ \mu \mathrm{L})$ & 2,940 & $4,000 \sim 10,800$ \\
Hemoglobin $(\mathrm{g} / \mathrm{dL})$ & 11.8 & $12.0 \sim 16.0$ \\
Platelet count $(/ \mu \mathrm{L})$ & 119,000 & $150,000 \sim 400,000$ \\
Prothrombin time $(\mathrm{s})$ & 12.10 & $9.2 \sim 12.3$ \\
ESR $(\mathrm{mm} / \mathrm{h})$ & 12.0 & $0.0 \sim 20.0$ \\
AST $(\mathrm{IU} / \mathrm{L})$ & 44 & $13.0 \sim 34.0$ \\
ALT $(\mathrm{IU} / \mathrm{L})$ & 22 & $5.0 \sim 46.0$ \\
Total protein $(\mathrm{g} / \mathrm{dL})$ & 8.7 & $6.0 \sim 8.0$ \\
Albumin $(\mathrm{g} / \mathrm{dL})$ & 3.2 & $3.3 \sim 5.3$ \\
Total bilirubin $(\mathrm{mg} / \mathrm{dL})$ & 0.7 & $0.4 \sim 1.5$ \\
Gamma-GT $(\mathrm{IU} / \mathrm{L})$ & 175 & $7.0 \sim 35.0$ \\
LDH $(\mathrm{IU} / \mathrm{L})$ & 277 & $119 \sim 247$ \\
ALP $(\mathrm{IU} / \mathrm{L})$ & 296 & $32 \sim 93$ \\
HBs Ag & Positive & Negative \\
HBe Ag & Negative & Negative \\
Anti HBe & Positive & Negative \\
HBV-RQ PCR $(\mathrm{IU} / \mathrm{mL})$ & 60.3 & $<20$ \\
Anti HCV & Negative & Negative \\
\hline Ag: antgen ALP: alkalne & &
\end{tabular}

Ag: antigen, ALP: alkaline phosphatase, ALT: alanine transaminase, AST: aspartate transaminase, ESR: erythrocyte sedimentation rate, GT: glutamyl transpeptidase, HBe: hepatitis B e, HBs: hepatitis B surface, HBV: hepatitis B virus, $\mathrm{HCV}$ : hepatitis $\mathrm{C}$ virus, $\mathrm{LDH}$ : lactate dehydrogenase, RQ PCR: real-time quantitative polymerase chain reaction.
Physical examination revealed mild tenderness on right upper quadrant area of abdomen without rigidity. Liver was slightly palpated below the margin of right rib. Laboratory results are shown in Table 1.

The abdomen sonogram showed that parenchymal echogenicity of the liver was coarse without space occupying lesion and the spleen was enlarged upto $12.63 \mathrm{~cm}$ (Figure 1A). Abdomen computed tomography (CT) scan revealed hepatosplenomegaly with heterogeneous enhancement and multiple lymph node enlargements around aorto-caval, para-aortic and peri-pancreatic space (Figure 1B). Liver stiffness measurement by transient elastography (Fibroscan ${ }^{\circledR}$; Echosens, Paris, France) was $24.2 \mathrm{kPa}$ which is compatible with liver fibrosis at stage 4 . The esophagogastroduodenoscopy was also done and it showed esophageal varix (small straight esophageal varix, F1), which is a clinical complication of portal hypertension.

Although she had been stable with chronic hepatitis B infection and lab findings were within normal range, the CT scan showed hepatosplenomegaly and multiple lymph node enlargements. Therefore, liver biopsy was needed to exclude other causes. Histology finding revealed chronic granulomatous inflammation showing multifocal multinucleated giant cells (Figure 2A). It did not show any necrosis in the granuloma, so sarcoidosis and drug reaction could be suspected. However, we could conclude the histology finding as a sarcoidosis because asteroid bodies were noted (Figure 2B). Acid fast bacilli stain and periodic acid Schiff stain were negative, therefore the possibility of mycobacterial infection or fungal infection was low (Figure 2C and 2D).

Positron emission tomography (PET) scan was also done and it showed numerous hyper-metabolic foci in the
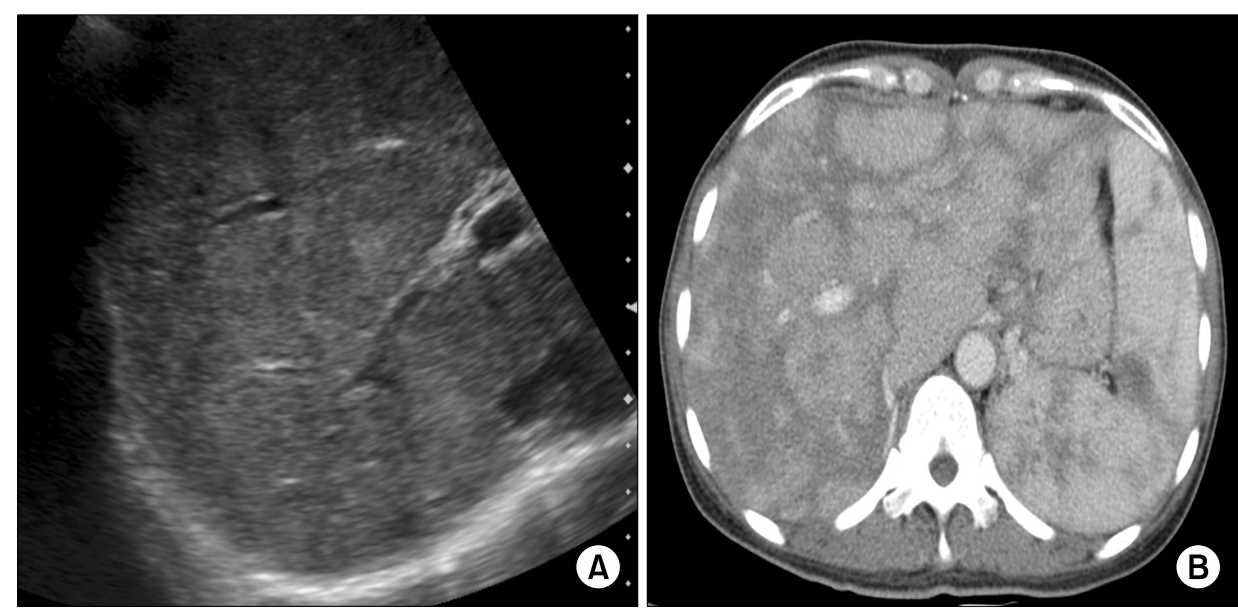

Figure 1. Abdomen sonogram (A) and abdomen computed tomography (CT) scan (B). Sonogram (A) reveals coarse parenchymal echogenicity of the liver. CT scan (B) shows heterogeneous enhancement in the enlarged liver and the spleen. 


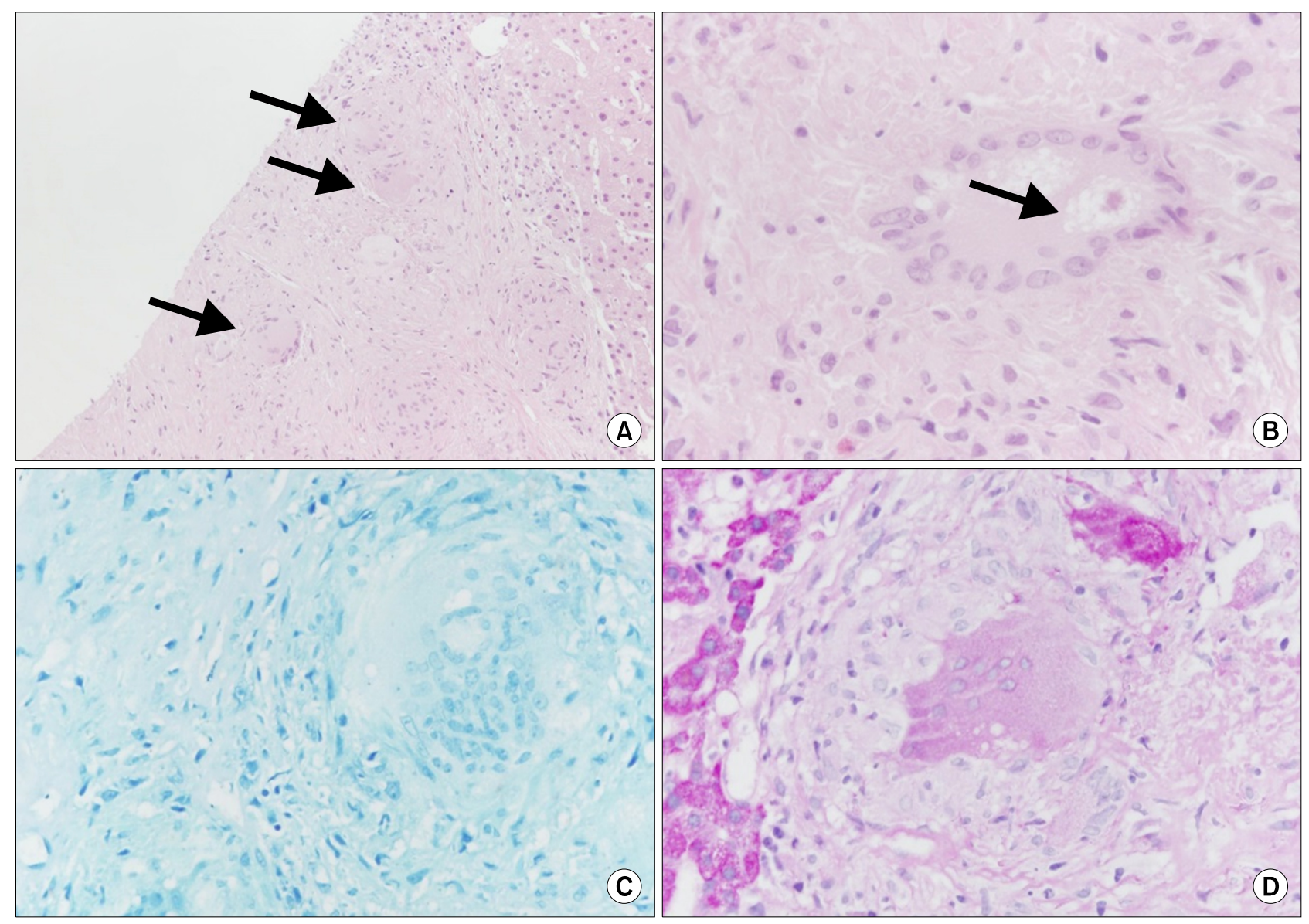

Figure 2. Liver biopsy showing the non-caseating granuloma (arrows) (A) and asteroid body (B). Special staining for acid fast bacilli $(A F B)(C)$ and periodic acid Schiff (PAS) (D) were negative (A: H\&E, $\times 100 ; B: H \& E, \times 400 ; C: A F B, \times 400 ; D: P A S, \times 400)$.

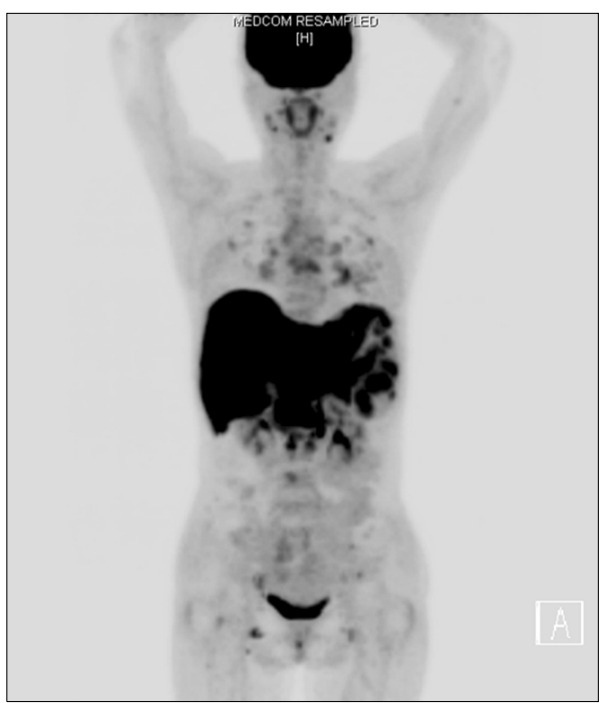

Figure 3. Positron emission tomography scan with multiple uptakes in the liver, spleen, lymph nodes, and bones. liver and spleen, multiple lymph nodes uptake and hyper-metabolic foci in bones including L3 vertebra, left iliac bone, sacrum and right proximal femur (Figure 3). Since thrombocytopenia abruptly occurred and progressed in addition to increased bone uptake on PET scan, bone marrow biopsy was done and there were no abnormal findings. Thrombocytopenia might have been due to the liver cirrhosis. However, other manifestations of liver cirrhosis such as hyperbilirubinemia, hypoalbuminemia and prothrombin time prolongation were not remarkable. Therefore we suspected that hepatic sarcoidosis with marked splenomegaly might have induced the thrombocytopenia [9].

Under the diagnosis of sarcoidosis, auto-immune markers and angiotensin-converting enzyme (ACE) level were checked. ACE level was elevated to $180 \mathrm{U} / \mathrm{L}$ (20 to 70 $\mathrm{U} / \mathrm{L}$ ) and auto-immune markers including antinuclear antibody and rheumatoid factor were negative.

She was diagnosed with sarcoidosis involving liver, lung 


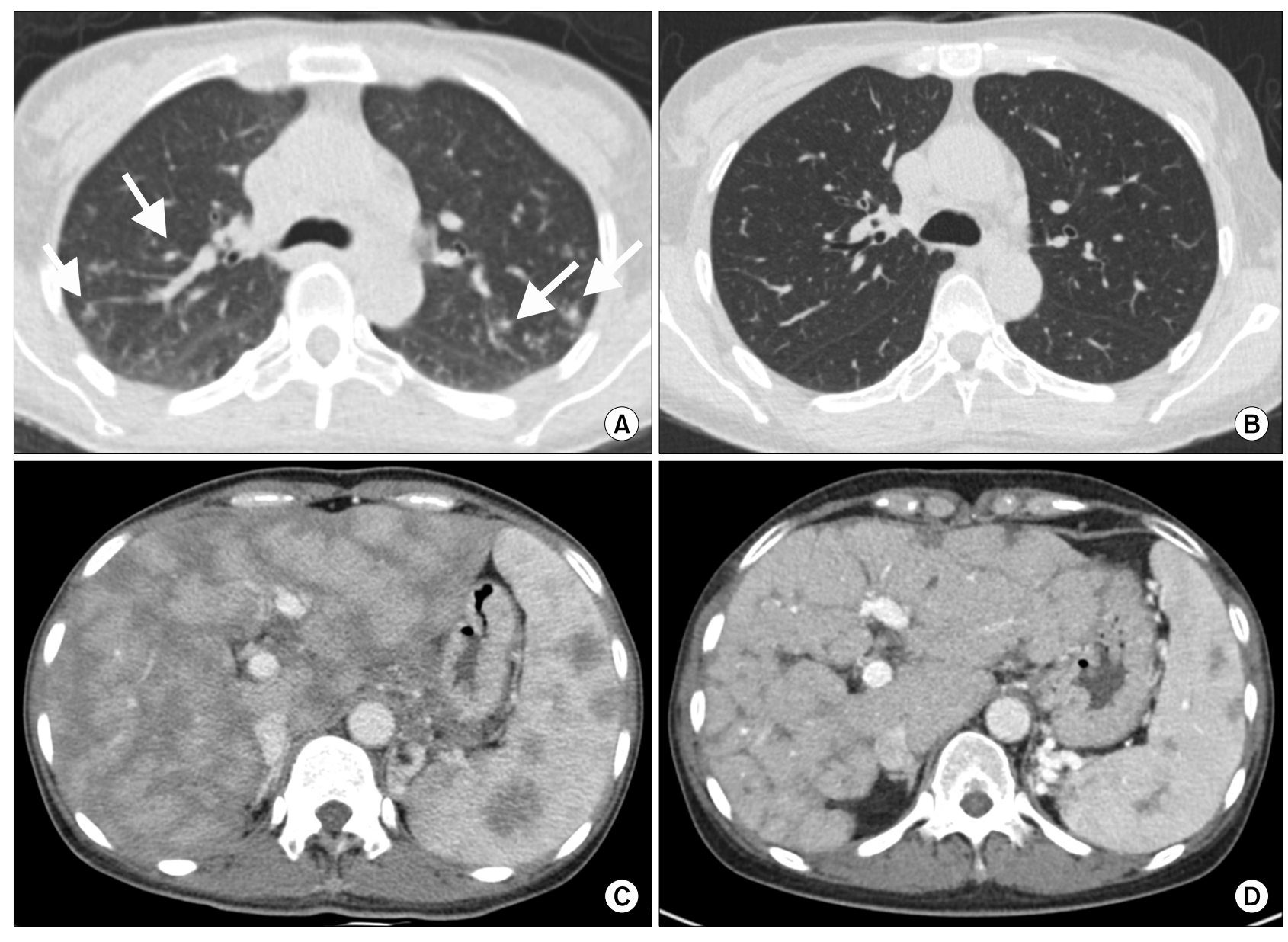

Figure 4. Chest computed tomography $(C T)$ scans $(A, B)$ and abdominal $C T$ scans $(C, D)$. CT scans at the time of diagnosis (A, C) showing multiple perilymphatic nodules in both lungs (arrows) and heterogeneous enhancement in liver and spleen with hepatosplenomegaly. CT scans (B, D) taken after steroid treatment, revealing near total resolution of perilymphatic nodules and decreased size of liver and spleen.

and multiple lymph nodes, but no other organ involvement was found in such as eyes, skin or joints. She began to receive prednisolone at a dose of $30 \mathrm{mg} / \mathrm{d}$. Follow-up CT scan was performed and it revealed improvement of sarcoidosis in liver as well as lymph nodes (Figure 4). The laboratory results were all within normal reference range. Prednisolone was tapered to a dose of $16 \mathrm{mg} / \mathrm{d}$ on the last visit.

\section{DISCUSSION}

So far, there have been many reports that described the association between sarcoidosis and HCV. The first case was reported by Blum et al. [10] in 1993. Also, IFN- $\alpha$ for the treatment of HCV was believed to provoke the development of sarcoidosis by inducing various autoimmune conditions and disorders of immune regulation [11]. In
1999, Belgodere et al. [12] first reported a case of a HCV patient with sarcoidosis who had never been treated with IFN- $\alpha$. It showed that IFN- $\alpha$ therapy may activate the development of sarcoidosis, but HCV infection itself also can induce sarcoidosis.

On the other hand, the report regarding the association between sarcoidosis and HBV is very rare; to our knowledge, there was only one case report by Husa et al. [13] in 2002. In that report, sarcoidosis was developed after the initiation of IFN- $\alpha$ for HBV treatment. But so far, there was no case report on sarcoidosis in patients with chronic HBV infection who were not treated by INF- $\alpha$.

In this case, the patient had been diagnosed with chronic HBV infection, but had never been treated by drugs including IFN- $\alpha$. Thus we guessed the possible link between hepatic sarcoidosis and HBV infection.

So far, there are a number of reports about the relation- 
ship between sarcoidosis and HCV infection. However, the studies regarding HBV infection is scarce. We speculate that the different cytokine profiles in HBV and HCV infection might be the reason for this different incidence of sarcoidosis. For example, higher amounts of IFN- $\gamma$ are secreted in HCV infection than in HBV infection [14]. And in the pathogenesis of sarcoidosis, high expression of T helper 1 cytokines such as IFN- $\gamma$ and interleukin-2 is noted [15].

However, the exact mechanism still remains unclear due to the lack of reports. But it can be reasonably assumed that the alterations in the pool of cytokines and immune cells caused by HBV infection may have a vicious influence on the immune regulation and in turn it can be a trigger for granuloma formation.

\section{SUMMARY}

This report describes the first case of hepatic sarcoidosis accompanied by portal hypertension and liver cirrhosis in a patient with INF- $\alpha$-naïve chronic HBV infection.

\section{CONFLICT OF INTEREST}

No potential conflict of interest relevant to this article was reported.

\section{REFERENCES}

1. Blich M, Edoute Y. Clinical manifestations of sarcoid liver disease. J Gastroenterol Hepatol 2004;19:732-7.

2. Tan CB, Rashid S, Rajan D, Gebre W, Mustacchia P. Hepatic sarcoidosis presenting as portal hypertension and liver cirrhosis: case report and review of the literature. Case Rep Gastroenterol 2012;6:183-9.

3. Rybicki BA, Iannuzzi MC. Epidemiology of sarcoidosis: recent advances and future prospects. Semin Respir Crit Care
Med 2007;28:22-35.

4. Kang EH. Sarcoidosis in Korea: revisited. J Korean Med Assoc 2008;51:925-32.

5. Brjalin V, Salupere R, Tefanova V, Prikk K, Lapidus N, Jõeste E. Sarcoidosis and chronic hepatitis C: a case report. World J Gastroenterol 2012;18:5816-20.

6. Baughman RP, Teirstein AS, Judson MA, Rossman MD, Yeager H Jr, Bresnitz EA, et al; Case Control Etiologic Study of Sarcoidosis (ACCESS) research group. Clinical characteristics of patients in a case control study of sarcoidosis. Am J Respir Crit Care Med 2001;164:1885-9.

7. Cremers J, Drent M, Driessen A, Nieman F, Wijnen P, Baughman R, et al. Liver-test abnormalities in sarcoidosis. Eur J Gastroenterol Hepatol 2012;24:17-24.

8. Ramos-Casals M, Mañá J, Nardi N, Brito-Zerón P, Xaubet A, Sánchez-Tapias JM, et al; HISPAMEC Study Group. Sarcoidosis in patients with chronic hepatitis $\mathrm{C}$ virus infection: analysis of 68 cases. Medicine (Baltimore) 2005;84: 69-80.

9. Mahévas M, Le Page L, Salle V, Lescure FX, Smail A, Cevallos R, et al. Thrombocytopenia in sarcoidosis. Sarcoidosis Vasc Diffuse Lung Dis 2006;23:229-35.

10. Blum L, Serfaty L, Wattiaux MJ, Picard O, Cabane J, Imbert J. Nodules hypodermiques sarcoïdosiques au cours d'une hépatite virale $\mathrm{C}$ traitée par Interféron alpha $2 \mathrm{~b}$. La Revue de Médecine Interne 1993;14:1161.

11. Adla M, Downey KK, Ahmad J. Hepatic sarcoidosis associated with pegylated interferon alfa therapy for chronic hepatitis C: case report and review of literature. Dig Dis Sci 2008;53:2810-2.

12. Belgodere X, Viraben R, Gorguet B, Allaouchiche B, Lieutaud O, Maestracci D. Guess what! Cutaneous sarcoidosis, Sjögren's syndrome and autoimmune thyroiditis associated with hepatitis C virus infection. Eur J Dermatol 1999;9:235-6.

13. Husa P, Klusáková J, Jancíková J, Husová L, Horálek F. Sarcoidosis associated with interferon-alpha therapy for chronic hepatitis B. Eur J Intern Med 2002;13:129-31.

14. Bertoletti A, D'Elios MM, Boni C, De Carli M, Zignego AL, Durazzo $M$, et al. Different cytokine profiles of intraphepatic $\mathrm{T}$ cells in chronic hepatitis $\mathrm{B}$ and hepatitis $\mathrm{C}$ virus infections. Gastroenterology 1997;112:193-9.

15. Moller DR. Cells and cytokines involved in the pathogenesis of sarcoidosis. Sarcoidosis Vasc Diffuse Lung Dis 1999; 16:24-31. 